\title{
Regional circulation patterns inducing coastal upwelling in the Baltic Sea
}

\author{
Ewa Bednorz ${ }^{1}$ (D) - Marek Półrolniczak ${ }^{1}$ - Arkadiusz M. Tomczyk ${ }^{1}$
}

Received: 20 January 2020 / Accepted: 18 January 2021 / Published online: 8 March 2021

(C) The Author(s) 2021

\begin{abstract}
Atmospheric feedback involved in the occurrence of coastal upwelling in a small semi-enclosed sea basin, i.e., the Baltic Sea, was analysed, and the regional circulation conditions triggering upwelling in different coastal sections were identified. Upwelling in the summer season (June-August, years 1982-2017) was recognized on the basis of sea surface temperature patterns. Circulation conditions were defined using (1) the established daily indices of zonal and meridional airflow and (2) the synoptic situation at sea level distinguished by applying rotated principal component analysis to sea level pressure data. The 12 daily synoptic patterns differed substantially in the intensity and location of their pressure centres. The mean seasonal frequency of upwelling was generally higher along the western Baltic shores than along the meridionally oriented eastern shores and varied from less than 10 to over 30\% along the more predestined coastal sections, i.e., the northwestern coast of the Gulf of Bothnia, the northern Gulf of Finland and the southern Swedish coast. Due to the variable orientations of coastlines, upwelling could occur under almost any prevailing wind direction, and thus, each of the classified synoptic patterns could induce upwelling in some coastal sections. As deduced from the pressure fields for each circulation pattern, mostly alongshore winds triggered upwelling, which is in line with the Ekman rule. With time, upwelling could also be induced by the stress of normal to the coastline seaward winds.
\end{abstract}

\section{Introduction}

The phenomenon of upwelling can be considered among the most evident examples of ocean-atmosphere coupling. Upwelling is defined as the ascending motion of subsurface water, by which water from deeper layers is transported into the surface as a result of horizontal divergence in the surface layers (AMS Glossary of Meteorology 2017; Lehmann and Myrberg 2008). Horizontal currents in the sea/ocean surface are always triggered by the above air motion, i.e., surface winds. In the Northern Hemisphere, coastal upwelling usually appears when the wind blows alongshore with the coast on its left (e.g., Lehmann and Myrberg 2008; Lehmann et al. 2012).

Ewa Bednorz

ewabedno@amu.edu.pl

Marek Półrolniczak

marekpol@amu.edu.pl

Arkadiusz M. Tomczyk

atomczyk@amu.edu.pl

1 Department of Meteorology and Climatology, Adam Mickiewicz University in Poznań, Poznań, Poland
Off-shore surface currents triggered by alongshore winds with perpendicular air and surface water motion are explained by Ekman's theory, which describes the rotation of the flow direction over horizontal layers with depth (Ekman 1905). The rotation, integral with the downward current, is derived from the impact of Coriolis and frictional forces, which turn to the right the direction of flow in the Northern Hemisphere. However, it has been argued that at small scales, the Earth's rotation has a negligible effect; therefore, in minor sea basins with a scale that is small for the Coriolis forces to dominate on the order of the Rossby radius, winds blowing from the land interior can also cause upwelling by pushing the surface currents offshore (Ekman 1905, p. 38-39 Plate 1; Bednorz et al. 2019). This may take place in the Baltic Sea, where the coastal upwelling scale is approximately $5-40 \mathrm{~km}$ offshore and $100 \mathrm{~km}$ alongshore, depending on the region (Lehmann et al. 2012).

Within the Baltic Sea, which is a semi-enclosed and relatively small basin with coastlines oriented in various directions, upwelling may occur in some coastal sections under any wind direction. Consequently, upwelling is frequent in the Baltic Sea and is best recognized in summer due to the pronounced thermal stratification of the water in the warm season. Warm surface waters that overlay colder deeper water 
masses are displaced towards the open sea, and the sea surface temperature (SST) at the coastline drops significantly due to the outflow of cold water from deeper layers. This makes the pattern of the SST field the best indicator of upwelling. The described water mixing by vertical displacement makes cold and nutrient-rich layers rise to the surface and fertilize surface waters. In this way, upwelling has an impact on biogeochemical processes and phytoplankton development (Vahtera et al. 2005; Zalewski et al. 2005; Kowalewski and Ostrowski 2005; Lehmann and Myrberg 2008; Omstedt et al. 2014). It also influences the local boundary climate, as cold surface water modifies the surface-atmosphere heat exchange by increasing the atmospheric heat loss and changing the stability of the marine boundary layer (Omstedt et al. 2014).

In the Baltic Sea, upwelling is considered to be a typical warm season phenomenon, and many studies on its occurrence have been conducted; these studies were based first on in situ data and later on satellite data (i.e., Horstmann 1983; Gidhagen 1987; Lass et al. 2003; Myrberg and Andrejev 2003; Kowalewski and Ostrowski 2005; Uiboupin and Laanemets 2009; Lehmann et al. 2012). Most such studies consider the upwelling statistics in different coastal regions, and much less studies focus on the impact of atmospheric forcing on vertical seawater currents. The influence of local and macroscale circulation patterns on seawater circulation and the occurrence of upwelling within the Baltic Sea were analysed by Lehmann et al. (2002). They considered the North Atlantic Oscillation (NAO) as a representation of macroscale circulation and introduced the Baltic Sea Index (BSI) as a local circulation indicator expressing the western flow intensity. Furthermore, Lehmann et al. (2012) recognized upwelling-favourable wind conditions along the Baltic Sea coast. Bychkova and Viktorov (1987) identified regions of coastal upwelling, and Bychkova et al. (1988) described synoptic situations associated with the occurrence of upwelling in different regions. Their findings were discussed by Bednorz et al. (2013, 2018), who identified local circulation patterns that induce and inhibit upwelling along the Polish and Latvian-Lithuanian coast.

The regional circulation patterns, which demonstrate different features of the pressure field, namely, the location of the centres of action and the magnitude of pressure gradients, govern the direction and strength of local winds, and in this way, they are essential for the process of upwelling. The abovementioned contribution of Bychkova et al. (1988) inspired contemporary studies with a primary aim to identify the regional circulation patterns that trigger upwelling in different parts of the Baltic Sea coast. Results contradictory to the findings of Bychkova et al. (1988) concerning southeastern Baltic coasts were obtained in studies by Bednorz et al. (2013, 2018), which encouraged authors to update the classification of synoptic situations favourable for upwelling in different coastal sections of the Baltic Sea.

\section{Area, data and methods}

The study area encompasses the entire Baltic Sea basin, incorporating 15 differently oriented coastal sections (Fig. 1b). These regions were distinguished following Bychkova and Viktorov (1987), who delimited 22 zones of coastal upwelling in the entire Baltic Sea (Fig. 1a). Some low-scale sections were excluded from this study due to the low resolution of the sea surface temperature (SST) data employed to the analysis.

Upwelling events were identified using the mean daily SST data derived from the NOAA OI SST V2 High Resolution Dataset provided by the NOAA/OAR/ESRL PSD, Boulder, CO, USA (available at: http://www.esrl.noaa.gov, Reynolds et al. 2007). These data have a spatial grid resolution of $0.25^{\circ}$ $\times 0.25^{\circ}$, which means ca. $11-16 \mathrm{~km}$ resolution along the parallels $54-66^{\circ} \mathrm{N}$ and $27.8 \mathrm{~km}$ resolution along meridians. This resolution seems to be sufficient to recognize upwelling events, as its length scale in most regions exceeds $100 \mathrm{~km}$, and its width scale varies from 5 to $40 \mathrm{~km}$, depending on the coastal section (Lehmann and Myrberg 2008); nonetheless, some upwelling events at small spatial scales may be undetectable. Despite their low spatial and temporal resolution, the NOAA OI SST V2 data have an advantage crucial for the climatological analysis, namely, the dataset has a length of over 30 years without any gaps. Thus, the complete set of daily mean SST data in $0.25^{\circ} \times 0.25^{\circ}$ grid points from the summer months (June-August) of the period 1982-2017 were used in this study, and grids located along coasts were considered in the selection of upwelling events (Fig. 1b). The analysis was limited to summer because the strongest thermal stratification of sea waters occurs in summer; thus, upwelling on the basis of SST is best recognized in this season. The SST differences between the grids closest to the coast and farther grids were computed. If the coastal waters were colder than open-sea waters, the difference had a negative value, indicating that upwelling probably took place. The preliminary calculative selection was revised by visual assessment. Maps of SST were plotted for each of the initially selected days, and when isotherms bent towards the sea, displaying significantly lower SST along the coast than in the surrounding open-sea waters, upwelling events were considered to occur in the relevant coastal section (examples in Fig. 2). The selection of upwelling events in the entire 36-year period allowed us to compute the mean seasonal upwelling frequency.

In synoptic climatology, which aims to relate atmospheric circulation to the surface environment, one of two approaches can be adopted: 'environment to circulation' or 'circulation to environment'. In the first approach, circulation classification is carried out using specific environment-based criteria set for a particular environmental phenomenon, and in the second approach, atmospheric circulation classification is performed and is then applied to an environmental phenomenon (Yarnal 
a

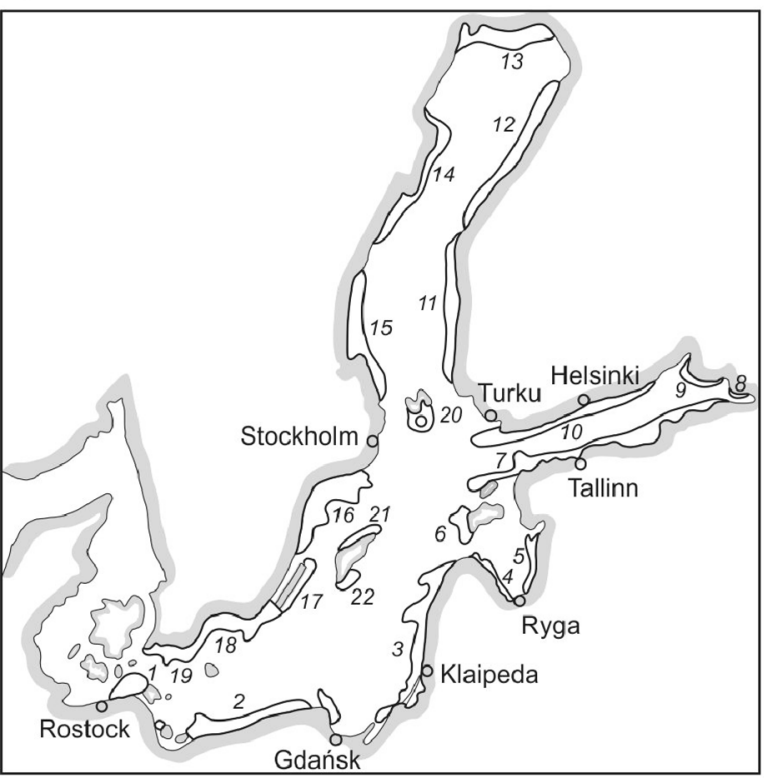

b

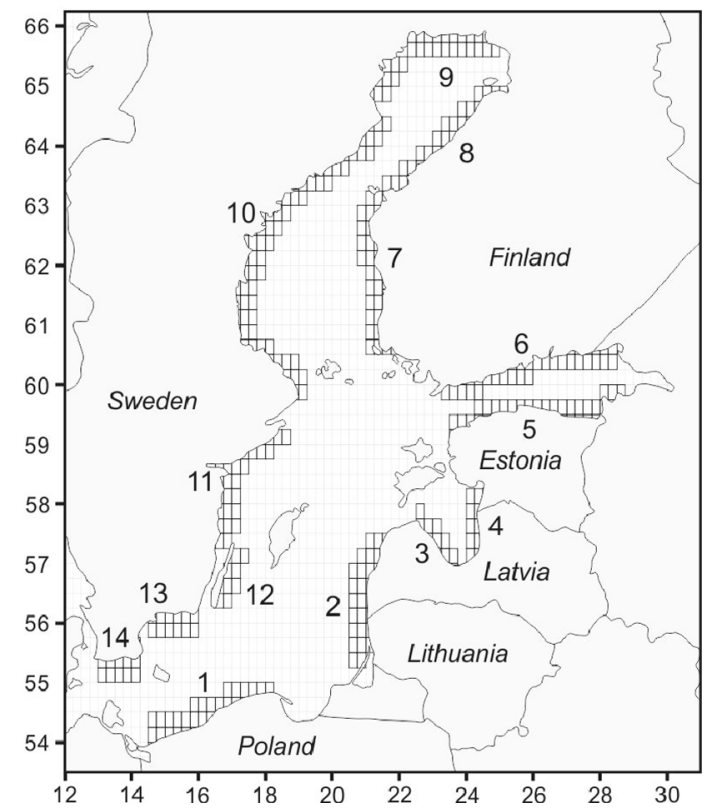

Fig. 1 Upwelling regions in the Baltic Sea redrawn from Bychkova et al. (1988) (a). Upwelling regions marked by pixels considered in this study while computing sea surface temperature (SST) differences (b)

1993; Yarnal et al. 2001; Dayan et al. 2012). This study used the second approach, initially defining the atmospheric circulation and then relating the classified circulation conditions to the occurrence of upwelling.

Daily sea level pressure (SLP) data with a spatial resolution of $2.5^{\circ} \times 2.5^{\circ}$, derived from the NCEP/NCAR (National
Centers for Environmental Prediction/National Center for Atmospheric Research) reanalysis dataset (Kalnay et al. 1996, https://psl.noaa.gov/data/gridded/data.ncep.reanalysis), were applied in the atmospheric part of the analysis. First, to define the general airflow direction over the Baltic Sea, daily indices of zonal $(\mathrm{Z})$ and meridional $(\mathrm{M})$ regional circulation
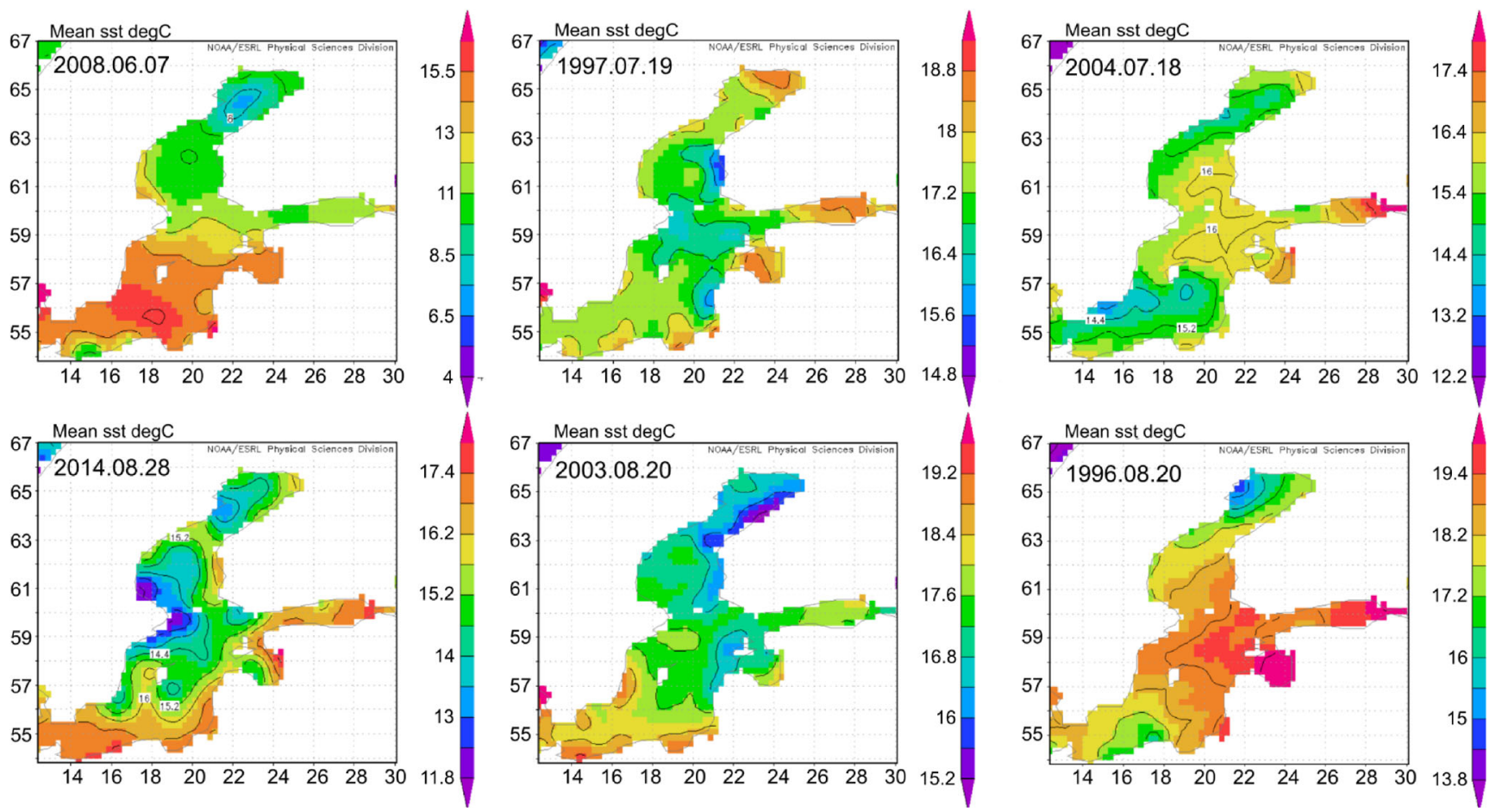

Fig. 2 Examples of sea surface temperature (SST) distributions showing upwelling in different regions of the southern Baltic Sea based on the NOAA OI SST V2 dataset 
were computed. Normalized daily SLP values in 22 grid points were employed. The $\mathrm{Z}$ index was calculated as the difference between the normalized SLP at $55^{\circ} \mathrm{N}$ (averaged for eight grid points indicated in Fig. 3) and $65^{\circ} \mathrm{N}$ (averaged, respectively), and the $\mathrm{M}$ index was calculated as the difference between the normalized SLP at $30^{\circ} \mathrm{E}$ (averaged for five grid points) and 12 . $5^{\circ} \mathrm{E}$ (averaged, respectively). Positive values of $\mathrm{Z} / \mathrm{M}$ indices indicated western/southern air flow over the study area. The Baltic Sea Index (BSI), a similar zonal circulation index constructed as the difference between the normalized SLP anomalies at the grid points $59.5^{\circ} \mathrm{N}$ and $10.5^{\circ} \mathrm{E}$ and $53.5^{\circ} \mathrm{N}$ and $14.5^{\circ} \mathrm{E}$, was used by Lehmann et al. (2002) to analyse the local atmospheric forcing on water circulation in the Baltic Sea.

Furthermore, daily regional circulation patterns in the summer were developed. To this end, rotated principal component analysis (PCA) was applied to the S-mode data matrix, where the grid points made up the variables and the daily normalized SLP values acted as the observations (Barnston and Livezey 1987; Wilks 2011; NCAR 2017). PCA is a multivariate statistical technique widely used in the atmospheric sciences to reduce a large number of variables to a few new variables, called principal components (PCs). In the case of this study, the PCs produced on the basis of normalized daily SLP fields represented the regional circulation types. The analysis gave the percentage of SLP variance explained by each PC, as well as the daily time series of eigenvalues for

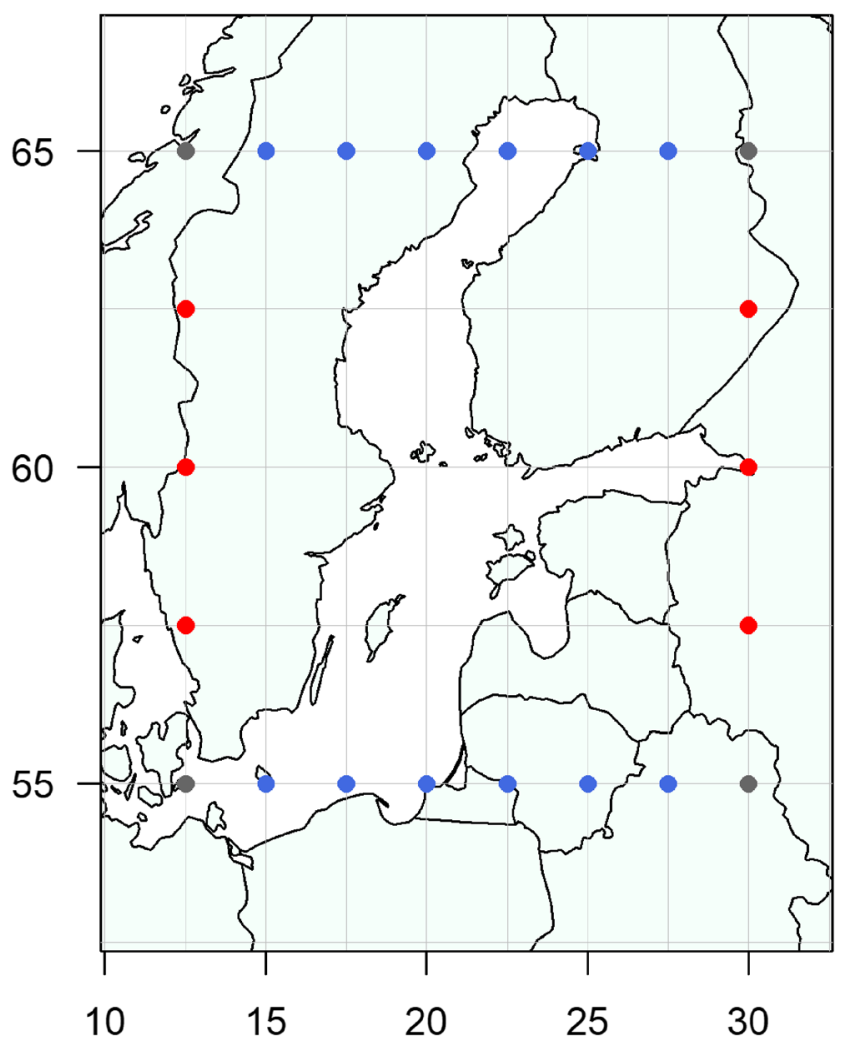

Fig. 3 Grid points used to calculate zonal (blue and grey dots) and meridional (red and grey dots) daily circulation indices each PC, which were used as daily indices of each circulation type. The number of PCs selected for rotation and used for further analysis was established considering the total amount of variability represented by the obtained PCs (Jolliffe 2002; Wilks 2011).

The obtained characteristics of circulation at a daily time scale (daily indices of Z, M and each PC) were analysed thereafter in terms of their relation to the occurrence of upwelling.

According to Zhurbas et al. (2008), different phases can be distinguished in the upwelling process. The 'active phase' takes place at the beginning of the process and is the induction of surface currents and ascending motion of subsurface water by strong alongshore winds. Afterwards, when the wind weakens but cold waters still persist at the surface, the 'relaxation phase' occurs. Assuming that upwelling-favourable circulation conditions appear during and before the 'active phase', only the days preceding the upwelling period and its first days were considered in searching the atmospheric patterns inducing the upwelling. Finally, increasing/decreasing chances of induced upwelling along all coastal sections in the positive and negative phases of each circulation type were mapped, and the synoptic patterns triggering upwelling in each coastal region were defined.

\section{Results}

\subsection{Frequency of upwelling}

The mean number of days in summer (June-August) with coastal upwelling varied spatially from over 30 days along the northwestern coast of the Gulf of Bothnia, the northern coast of the Gulf of Finland and the southern coast of Sweden to less than 10 days in some parts of the southeastern Baltic Sea coast, namely, the Polish, Lithuanian, Latvian and Estonian coastal sections. The upwelling frequency in single pixels ranged from over 40 to less than 5\% (Fig. 4).

In addition to spatial variability, the number of days with upwelling fluctuated from year to year, and the mean daily percentage of coastal sections with upwelling in each summer ranged from 18.5 to approximately $50 \%$ (Fig. 5). Among the 3312 days analysed in the 36-year period, there were only 19 days during which coastal upwelling did not occur in the Baltic Sea. As many as 129 days with upwelling (approximately 3.5 per season) occurred in one-third of the analysed pixels, and 544 days (approximately 15 per season) with upwelling occurred in one-fourth of the pixels. The seasonal number of days with upwelling in a particular coastal region may be as low as zero or as high as 92 or 91 days, such as in 1999 and 2016 along the northern coast of the Gulf of Finland, meaning that the upwelling phenomenon persisted all summer. 
Fig. 4 Frequency of coastal upwelling in the summers of the period 1982-2017 based on the mean daily SST values

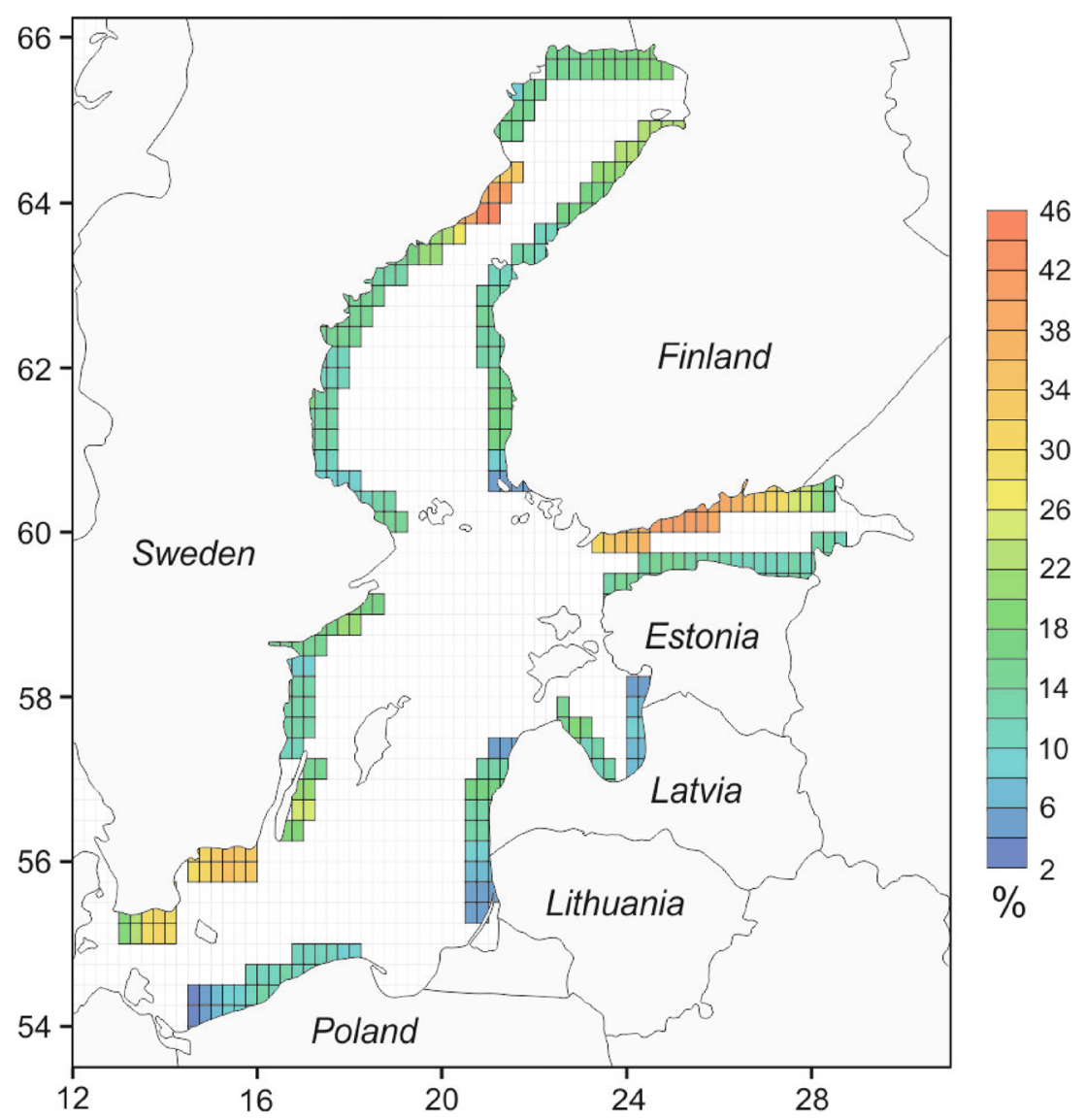

\subsection{Synoptic conditions inducing upwelling}

To recognize the atmospheric conditions that trigger upwelling in different parts of the Baltic Sea, circulation patterns were first determined. This was accomplished in two ways: (1) by computing daily zonal (Z) and meridional (M) circulation indices and (2) by producing daily regional circulation patterns. To obtain daily regional circulation patterns, the rotated PCA was applied to a standardized SLP mean daily data matrix, and six newly produced variables, i.e., principal components (PCs), were chosen. The number of new variables was established considering the percentage of the total variance of the SLP field represented by the first $n$ PCs, which amounted to $81 \%$ for $n=6$ (Jolliffe 2002; Wilks 2011). Ultimately, 12 substantially different circulation patterns were established, considering the positive ( $\mathrm{PC}$ index $>1$ ) and negative (PC index $<-1$ ) phases of each of the six PCs.
Fig. 5 Mean daily percentage of pixels where upwelling was observed, computed for summer months (June-August)

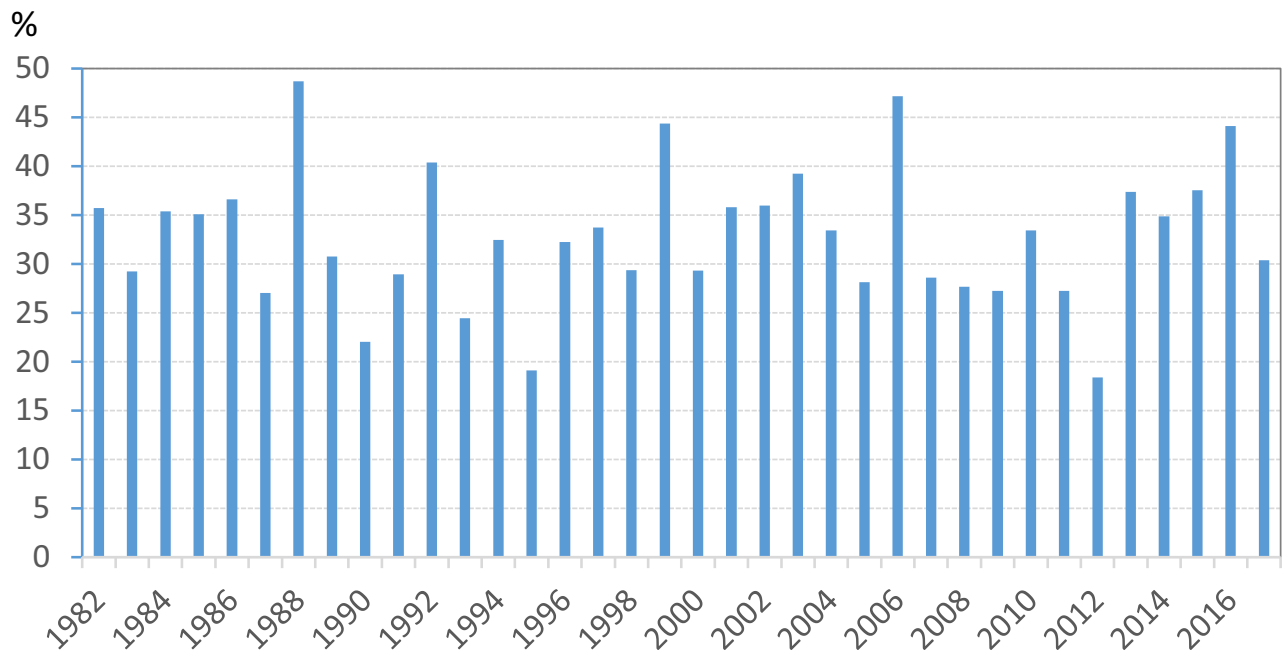


According to the calculation method, positive/negative values of the $\mathrm{Z}$ index indicated western/eastern airflow, and positive/negative values of the $\mathrm{M}$ index corresponded to northern/southern airflow. Some of the 12 circulation patterns were significantly correlated with zonal/meridional circulation, which influenced further results (Table 1).

The obtained characteristics of circulation at a daily time scale (indices of Z, M and positive/negative phase of each PC) were analysed thereafter in terms of their relation to upwelling occurrence. To determine the atmospheric conditions that induce upwelling, only 1 day preceding the occurrence of upwelling and the first 2 days of upwelling, constituting the 'active phase' (according to Zhurbas et al. 2008), were selected.

In the positive phase of $Z$, the sustained western airflow provided favourable conditions for the induction of upwelling along the western and northern Baltic Sea coastlines (W in Fig. 6). This airflow essentially amplified the chance of ascending subsurface water along the northern coast of the Gulf of Finland by $40-50 \%$ and along the southeastern coast of Sweden/eastern cost of Oland by more than $30 \%$. At the same time, western circulation suppressed the chance of coastal upwelling along the southern and eastern coasts. A negative phase of $Z$, related to the eastern circulation, triggered coastal upwelling in the southern and eastern sections of the Baltic Sea basin (E in Fig. 6). For example, it increased the chance of upwelling along the southern coast of the Gulf of Finland by over $30 \%$ and on the western side of the Gulf of Riga by 60 $70 \%$.

Meridional circulation mostly influenced the meridionally oriented coastal sections. In the positive phase associated with the northern airflow, the chance of upwelling formation increased by $30-50 \%$ along the Lithuanian-Latvian coast, while the intensified southern flow during the negative $M$ phase induced upwelling on the western side of the Gulf of Bothnia, where the chance of upwelling formation increased by over $40 \%$ in some pixels.

Among the circulation patterns distinguished by PCA, PC1 explained the highest percentage of the total SLP variance in the analysed region $(21.5 \%$ ) (Fig. S1 in supplementary material). In the positive phase ( $\mathrm{PC} 1$ index $>1$ ), a highpressure system with a centre located over the Barents Sea extended over northern Europe and encompassed the northern part of the Baltic Sea, activating eastern and southeastern airflow in this area (PC1 P in Fig. 7 and Fig. S2 in supplementary material). This indicated that there were winds parallel to the coast along the southwestern coast of the Gulf of Bothnia and southern coast of the Gulf of Finland that triggered upwelling. The same effect was caused by an offshore flow at the northern coast of the Gulf of Bothnia. The cyclonal system in the negative phase of PC1 (PC1_N in Fig. 7) was stronger and had a greater range than its anticyclonal counterpart from the positive phase and therefore influenced the circulation of seawater over a larger part of the Baltic Sea. The western airflow over the entire Baltic Sea basin suppressed upwelling formation along the northeastern coast of the Gulf of Bothnia and the southern side of the Gulf of Finland and, at the same time, enhanced the ascending motion of the subsurface waters at the northern side of the Gulf of Finland and along the southwestern Baltic coasts.

PC2 explained $16.7 \%$ of the total SLP variance in the analysed region, and in the positive phase, it revealed a lowgradient SLP field over the Baltic Sea (PC2_P in Fig. 7). The clockwise air circulation around the weak secondary lowpressure centre located over the Danish straits suppressed upwelling along the meridionally oriented southeastern Baltic coasts. In the PC2 negative phase, there were high-pressure gradients over the entire Baltic Sea basin with eastern and northeastern winds blowing (PC2_N in Fig. 7), and such conditions strongly modified the chance of upwelling formation. It increased along the northern and western coasts and decreased along most of the southern and eastern coastal sections.

The positive phase of PC3 (explaining 15.9\% of the total SLP variance) indicated that there was an anticyclonic situation with a centre of action located over southern Norway (PC3_P in Fig. 7). The clockwise circulation around the high-pressure centre induced upwelling along the entire southern, eastern and northern coastlines, excluding the gulfs of Finland and Riga. The negative phase revealed opposite pressure conditions, and the deep cyclonic system encompassing the entire Baltic Sea region had an even stronger impact on coastal upwelling formation than its anticyclonic counterpart in the positive phase of $\mathrm{PC} 3$ ( $\mathrm{PC} 3 \_\mathrm{N}$ in Fig. 7). Counterclockwise air circulation around the centre over south Scandinavia enhanced upwelling along the southeastern Swedish coasts and along the northern side of the Gulf of Finland. Upwelling formation was hindered in the
Table 1 Pearson's correlation coefficients between indices of the regional circulation patterns (PC1-PC6) and zonal (Z)/ meridional $(\mathrm{M})$ circulation indices

\begin{tabular}{lllllll}
\hline $\begin{array}{l}\text { Circulation patterns } \rightarrow \\
\text { Circulation indices } \downarrow\end{array}$ & PC1 & PC2 & PC3 & PC4 & PC5 & PC6 \\
\hline $\mathrm{Z}$ & -0.485 & -0.364 & -0.086 & -0.001 & 0.069 & $\mathbf{0 . 5 7 3}$ \\
$\mathrm{M}$ & -0.209 & 0.221 & 0.410 & -0.184 & $\mathbf{- 0 . 7 3 6}$ & -0.070 \\
\hline
\end{tabular}

Moderate correlation in italics; strong correlation in bold 

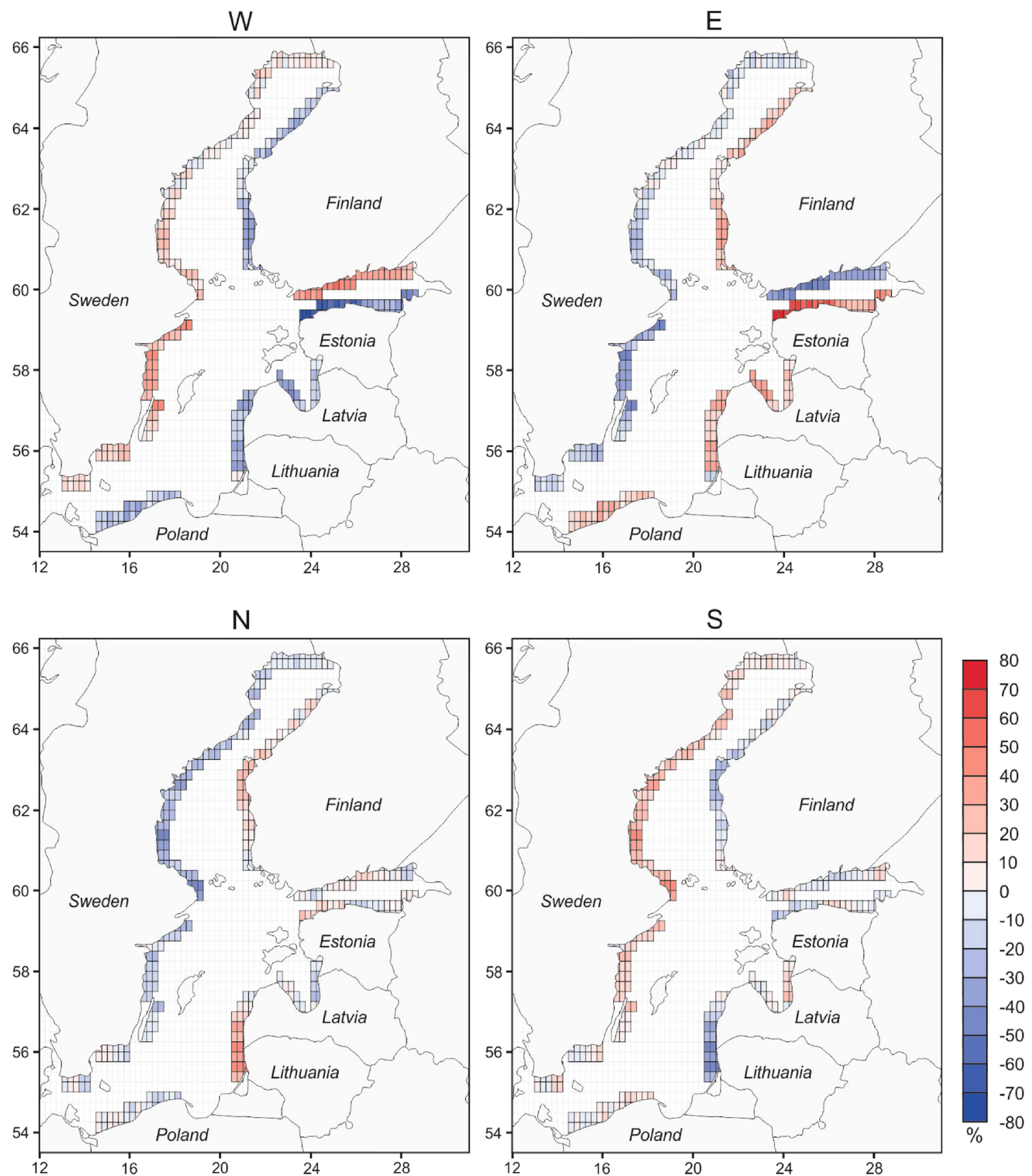

Fig. 6 Anomalies of the frequency of upwelling formation under western $(W)$, eastern $(E)$, northern $(N)$ and southern $(S)$ circulation

southeastern regions (Polish, Lithuanian and Latvian coasts) and along the northernmost coast of the Gulf of Bothnia.

The remaining regional circulation types, namely, PC4PC6, explained less than $24 \%$ of the SLP variance within the analysed region (PC4, 9.9\%; PC5, 8.2\%; PC6, 5.8\%). The positive phase of PC4 exhibited a weak high-pressure system that encompassed most of the Baltic Sea (PC4 P in Fig. 8 and Fig. S3 in supplementary material). Only the westernmost part of the basin remained out of the anticyclonic system, comprising the eastern sector of a deep low (with a centre over the British Islands) where southern airflow prevailed. Some influence of the PC4_P pattern on upwelling formation was observed in this section. Upwelling was inhibited along the zonally oriented southern Swedish coast and was enhanced along the Polish coast. Additionally, the negative phase of PC4 had a weak impact on seawater circulation in the Baltic Sea. A weak low with a centre located over the Gulf of Bothnia inhibited upwelling along the southwestern coast of the gulf (PC4 N in Fig. 8). A greater pressure gradient was observed in the southwestern part of the sea and along the zonally oriented southern Swedish coast, where favourable conditions for upwelling were observed. 

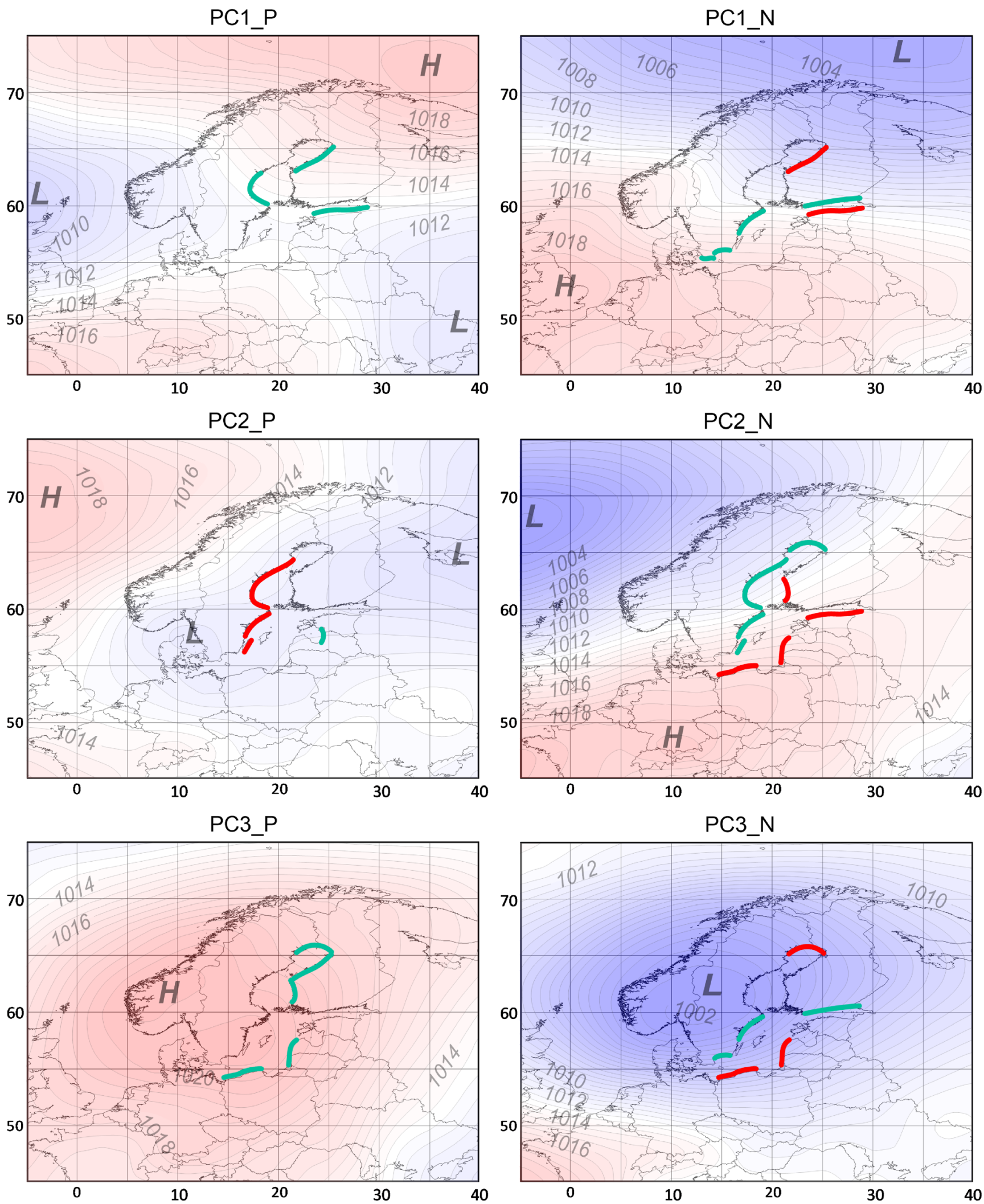

Fig. 7 SLP ( $\mathrm{hPa}$ ) composite anomaly maps for the positive (left column) and negative (right column) phases of the first three regional circulation types (PC1-PC3) distinguished on the basis of PCA. A positive/negative

phase means a daily PC index $>1 /<-1$. Coastal regions where the chance of upwelling formation increases/decreases by at least $30 \%$ are marked with a green/red line 

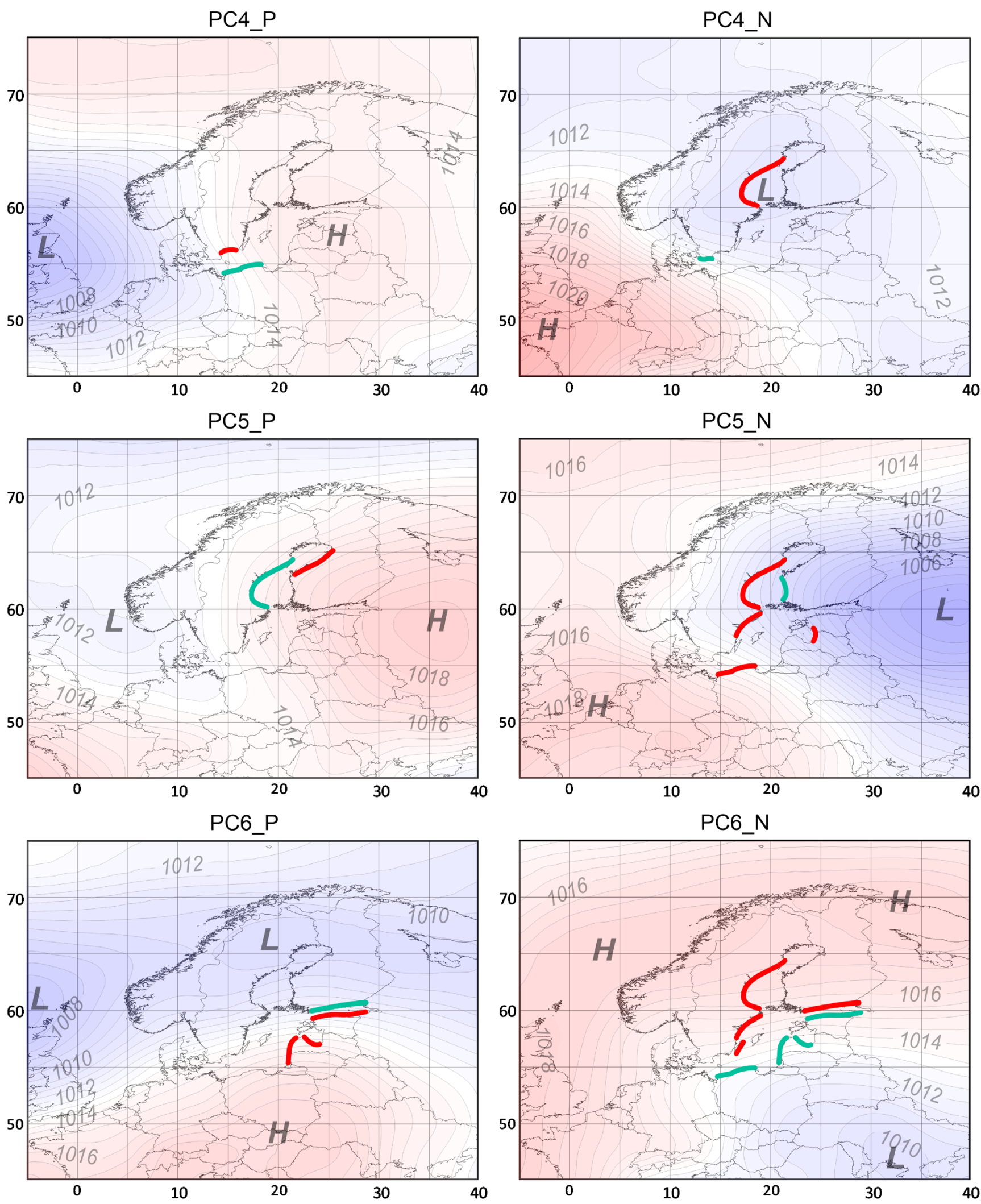

Fig. 8 The same as in Fig. 7, but for PC4-PC5

A positive phase of PC5 revealed a high-pressure system extending over east Europe and encompassing most of the
Baltic Sea (PC5_P in Fig. 8). Southern and southwestern air flow around the anticyclonic centre made favourable 
conditions for upwelling in the western coast of the Gulf of Bothnia and inhibited upwelling along the northeastern coast. An opposite pressure pattern in the PC5 negative phase, i.e., a vast and deep low in eastern Europe, caused strong northern and northwestern flow over the Baltic Sea basin (PC5_N in Fig. 8). It suppressed upwelling formation along the western side of the Baltic Sea, namely, at the eastern coasts of Sweden and at the Polish coast. Northern circulation enhanced coastal upwelling in the southeastern region of the Gulf of Bothnia.

The pressure pattern in the positive phase of the last PC amplified western and northwestern airflow, which was favourable for upwelling along the northern coast and unfavourable for upwelling along the southern coast of the Gulf of Finland (PC6_P in Fig. 8). Upwelling was also suppressed in the gulf of Riga and along the Lithuanian-Latvian coast. In the negative phase, an opposite circulation pattern triggered eastern airflow, which amplified the chance of upwelling formation in coastal regions in the southeastern part of the Baltic Sea. At the same time, the chance of upwelling decreased along meridionally oriented coasts in the western part of the Baltic basin and along the northern Gulf of Finland coast (PC6_N in Fig. 8).

Each of the distinguished circulation patterns prominently influenced (triggers or inhibits) the formation of upwelling in Baltic Sea coastal regions. Conversely, for each coastal region, circulation patterns that triggered or inhibited upwelling could be identified. The offshore surface sea currents and ascending motion of sea waters were mostly related to the atmospheric circulation patterns along the zonally oriented coastal sections, such as in the Gulf of Finland and the Polish coast. Among the meridionally oriented coastal regions, the western
Baltic Sea coasts (from approximately $58^{\circ}$ to $62.5^{\circ}$ latitude $\mathrm{N})$, a relatively weak reaction to atmospheric forcing was detected in the northern and eastern Gulf of Bothnia and in the Gulf of Riga (Table 2, Figs. S2 and S3).

\section{Conclusions and discussion}

The mean frequency of coastal upwelling in the Baltic Sea during summer varies from less than $10 \%$ in regions located in the southern and eastern parts of the sea basin to over $30 \%$ along the more defined coastal sections, i.e., the northwestern coast of the Gulf of Bothnia, the northern Gulf of Finland and the southern Swedish coast. The latter two coastal sections are zonally oriented, and westerlies, which prevail in this region, blow alongshore, with the coast on their left. This, according to Ekman theory, provides the best conditions for upwelling formation. Upwelling is generally more frequent along the western shores than along meridionally oriented eastern shores, which suggests that westerlies, as offshore winds along the western coasts, are highly relevant in the occurrence of the upwelling phenomenon. A similar pattern was reported by Lehmann et al. (2012), who analysed upwelling frequency for the years 1990-2009 from May to September. According to Kowalewski and Ostrowski (2005), along the Polish coast, downwelling of coastal waters is more frequent than upwelling due to prevailing westerly winds (also Myrberg and Andrejev 2003).

While the frequency of upwelling in the Baltic Sea has been well recognized in previous studies (e.g., Myrberg and

Table 2 Circulation patterns (displayed in Figs. 7 and 8) inducing and inhibiting upwelling in the Baltic Sea coastal regions displayed and numbered in Fig. 1

\begin{tabular}{|c|c|c|c|}
\hline & \multirow[t]{2}{*}{ Coastal region } & \multicolumn{2}{|l|}{ Circulation patterns } \\
\hline & & Inducing upwelling & Inhibiting upwelling \\
\hline 1 & Polish coast & PC3_P; PC4_P; PC6_N & PC2_N; PC3_N; PC4_N; PC5_N \\
\hline 2 & Lithuanian-Latvian coast & PC3_P; PC6_N & PC3_N; PC6_P \\
\hline 3 & Western coast of the Gulf of Riga & PC6_N & PC6_P \\
\hline 4 & Eastern coast of the Gulf of Riga & $\mathrm{PC} 2 \_\mathrm{P}$ & PC5_N \\
\hline 5 & Southern coast of the Gulf of Finland & PC1_P; PC6_N & PC1_N; PC2_N; PC6_P \\
\hline 6 & Northern coast of the Gulf of Finland & PC1_N; PC3_N; PC6_P & PC6_N \\
\hline 7 & Eastern coast of the Gulf of Bothnia & PC3_P; PC5_N & PC2_N; PC3_N; PC4_N; \\
\hline 8 & Northeastern coast of the Gulf of Bothnia & PC1_P; PC3_P & PC1_N; PC5_P \\
\hline 9 & Northern coast of the Gulf of Bothnia & PC2_N; PC3_P & PC3_N \\
\hline 10 & Southwestern coast of the Gulf of Bothnia & PC1_P; PC5_P; PC6_N & $\mathrm{PC} 2 \_\mathrm{P} ; \mathrm{PC} 2 \_\mathrm{N} ; \mathrm{PC} 5 \_\mathrm{N}$ \\
\hline 11 & Southeastern coast of Sweden & PC1_N; PC2_N; PC3_N & PC2_P; PC5_N; PC6_N \\
\hline 12 & Eastern coast of Oland & $\mathrm{PC} 2 \_\mathrm{N}$ & PC2_P; PC6_N \\
\hline 13 & Coast of Bleking County (Sweden) & $\mathrm{PC} 1 \_\mathrm{N} ; \mathrm{PC} 3 \_\mathrm{N}$ & PC4_P \\
\hline 14 & Southern coast of Scania County (Sweden) & $\mathrm{PC} 1 \_\mathrm{N}$ & PC4_N \\
\hline
\end{tabular}


Andrejev 2003; Kowalewski and Ostrowski 2005; Lehmann et al. 2012), less attention has been paid to the atmospheric circulation feedback of upwelling. In several studies, the surface wind direction has been emphasized as relevant to the surface and deep seawater currents (i.e., Urbański 1995; Myrberg and Andrejev 2003; Zurbas et al. 2004; Lehmann and Myrberg 2008). Lehmann et al. (2002) recognized the influence of intensified westerly airflow related to the positive phase of the NAO on the upwelling or downwelling processes in different Baltic Sea regions. However, the Baltic Sea Index (BSI), computed as the difference in normalized SLP anomalies between Szczecin (Poland) and Oslo (Norway), was better than NAO as an indicator of the western flow intensity over the Baltic Sea region (Lehmann et al. 2002).

The main goal of this study, namely, the recognition of synoptic conditions (i.e., pressure patterns) that determine the occurrence of upwelling in different coastal regions, was inspired by the work of Bychkova et al. (1988). They described 11 different synoptic situations favourable for upwelling in 22 Baltic coastal regions that had been distinguished in an earlier study (Bychkova and Viktorov 1987). Some results contradictory to the findings of Bychkova et al. (1988) concerning southeastern Baltic coasts obtained in studies by Bednorz et al. $(2013,2018)$ encouraged the authors to update the classification of synoptic situations favourable for upwelling in different coastal sections of the Baltic Sea.

It must be emphasized that the circulation patterns that trigger upwelling were the basic subject of the present research. These patterns appear before the occurrence of upwelling and during the first days of upwelling, a period recognized by Zhurbas et al. (2008) as the 'active phase', in which off-shore surface currents and ascending motion of the subsurface water are induced by strong alongshore (or off-shore) winds. The 'relaxation phase', when cold waters persist at the surface but the wind weakens, may be accompanied by different air pressure patterns. The approach employed in the present study better reflects the atmospheric forcing of upwelling and explains differences between the results obtained in this study and in the study by Bychkova et al. (1988).

It was proven that in a small and semi-enclosed basin such as the Baltic Sea, due to the variable orientations of coastlines, upwelling occurs under wind in almost any direction, and each of the classified circulation types can induce offshore surface sea currents, which enhance the upward motion of subsurface water. As can be deduced from the pressure fields constructed for each circulation pattern, mostly alongshore winds trigger upwelling, which is in line with the Ekman rule. However, upwelling can also be induced by the stress of normal to coastal seaward winds, as mentioned in several previous studies (Myberg and Andrejev 2003; Karstensen et al. 2014; Krężel et al. 2005).

Supplementary Information The online version contains supplementary material available at https://doi.org/10.1007/s00704-021-03539-7.

Acknowledgements NCEP Reanalysis data was provided by the NOAA/OAR/ESRL PSL, Boulder, Colorado, USA, from their Web site at https://psl.noaa.gov/.

Authors' contribution Ewa Bednorz designed and directed the project, wrote most of the article, and proceeded part of the computation and drawing most of the figures; Marek Półrolniczak processed and analysed the source data and prepared appropriate figures; Arkadiusz M. Tomczyk participated in writing and editing the manuscript as well as in computation and drawing figures.

Funding This work was supported by the National Science Foundation. Poland (grant number 2016/21/B/ST10/01440).

Data availability All calculated data are available on request at authors resources.

\section{Declarations}

Competing interests The authors declare no competing interests.

Code availability None

\section{References}

American Meteorological Society (2017) Glossary of meteorology. Available online at http://glossary.ametsoc.org/wiki/climatology.

Barnston AG, Livezey RE (1987) Classification, seasonality and persistence of low-frequency atmospheric circulation patterns. Mon Wea Rev 115:1083-1126

Bednorz E, Półrolniczak M, Czernecki B (2013) Synoptic conditions governing upwelling along the Polish Baltic coast. Oceanologia 55(4):767-785

Bednorz E, Półrolniczak M, Czernecki B, Tomczyk AM (2018) Atmospheric forcing of upwelling along the south-eastern Baltic coast. Baltica 31:73-85

Bednorz E, Półrolniczak M, Czernecki B, Tomczyk AM (2019) Atmospheric forcing of coastal upwelling in the southern Baltic Sea basin. Atmosphere 10(327). https://doi.org/10.3390/ atmos 10060327

Bychkova I, Viktorov S (1987) Use of satellite data for identification and classification of upwelling in the Baltic Sea. Oceanology 27(2):158 162

Bychkova I, Viktorov S, Shumakher D (1988) A relationship between the large scale atmospheric circulation and the origin of coastal upwelling in the Baltic. Meteorologiya i Gidrologiya 10:91-98 (in Russian)

Dayan U, Tubia A, Levy I (2012) On the importance of synoptic classification methods with respect to environmental phenomena. Int $\mathrm{J}$ Clim 32:681-694 
Ekman VW (1905) On the influence of the earth's rotation on oceancurrents. Ark Mat Astr Fys 2:1-52

Gidhagen L (1987) Coastal upwelling in the Baltic Sea — satellite and in situ measurements of sea-surface temperatures indicating coastal upwelling. Estuar Coast Shelf Sci 24:449-462

Horstmann U (1983) Distribution patterns of temperature and water colour in the Baltic Sea as recorded in satellite images: indicators for phytoplankton growth. Berichte Institut für Meereskunde, Kiel

Jolliffe IT (2002) Principal component analysis, 2nd edn. Springer, Berlin

Kalnay E, Kanamitsu M, Kistler R, Collins W, Deaven D, Gandin L, Iredell M, Saha S, White G, Woollen J, Zhu Y, Leetmaa A, Reynolds R, Chelliah M, Ebisuzaki W, Higgins W, Janowiak J, Mo KC, Ropelewski C, Wang J, Jenne R, Joseph D (1996) The NMC/NCAR 40-year reanalysis project. B Am Meteorol Soc 77: $437-471$

Karstensen J, Liblik T, Fischer J, Bumke K, Krahmann G (2014) Summer upwelling at the Boknis Eck time-series station (1982 to 2012) - a combined glider and wind data analysis. Biogeosciences 11:36033617

Kowalewski M, Ostrowski M (2005) Coastal up- and downwelling in the southern Baltic. Oceanologia 47(4):453-475

Krężel A, Ostrowski M, Szymelfenig M (2005) Sea surface temperature distribution during upwelling along the Polish Baltic coast. Oceanologia 47(4):415-432

Lass HU, Schmidt T, Seifert T (2003) Hiddensee upwelling field measurements and modelling results. ICES Coop Res Rep 257:204-208

Lehmann A, Myrberg K (2008) Upwelling in the Baltic Sea - a review. J Mar Syst 74:3-12

Lehmann A, Krauss W, Hinrichsen HH (2002) Effects of remote and local atmospheric forcing on circulation and upwelling in the Baltic Sea. Tellus 54A:299-316

Lehmann A, Myrberg K, Höflich K (2012) A statistical approach to coastal upwelling in the Baltic Sea based on the analysis of satellite data for 1990-2009. Oceanologia 54(3):369-393

Myrberg K, Andrejev O (2003) Main upwelling regions in the Baltic Sea - a statistical analysis based on three-dimensional modelling. Boreal Environ Res 8:97-112
NCAR (National Center for Atmospheric Research) Staff (Eds) (2017) The climate data guide: Hurrell North Atlantic Oscillation (NAO) Index (PC-based). https://climatedataguide.ucar.edu/climate-data/ hurrell-north-atlantic-oscillation-nao-index-pc-based

Omstedt A, Elken J, Lehmann A, Leppäranta M, Meier HEM, Myrberg K (2014) Rutgersson A. Progress in physical oceanography of the Baltic Sea during the 2003-2014 period. Progr Oceanogr 128: 139-171

Reynolds RW, Smith TM, Liu C, Chelton DB, Casey KS, Schlax MG (2007) Daily high-resolution-blended analyses for sea surface temperature. J Climate 20:5473-5496

Uiboupin R, Laanemets J (2009) Upwelling characteristics derived from satellite sea surface temperature data in the Gulf of Finland, Baltic Sea. Boreal Environ Resn.d. 14, 297-304.

Urbański JA (1995) Upwellings of the Polish coast of the Baltic Sea. Przegląd Geofizyczny 40(2):141-153 (in Polish)

Vahtera E, Laanemets J, Pavelson J, Huttunen M, Kononen K (2005) Effect of upwelling on the pelagic environment and bloomforming cyanobacteria in the western Gulf of Finland. Baltic Sea. J Mar Syst 58(1-2):67-82

Wilks DS (2011) Statistical methods in the atmospheric sciences, 3rd edn. Academic Press, Oxford

Yarnal B (1993) Synoptic climatology in environmental analysis. Belhaven Press, London

Yarnal B, Comrie AC, Frakes B, Brown DP (2001) Developments and prospects in synoptic climatology. Int J Clim 21:1923-1950

Zalewski M, Ameryk A, Szymelfenig M (2005) Primary production and chlorophyll a concentration during upwelling events along the Hel Peninsula (the Baltic Sea). Oceanol Hydrobiol St 34(2):97-113

Zhurbas V, Lannemets J, Vahtera E (2008) Modeling of the mesoscale structure of coupled upwelling/downwelling events and the related input to the upper mixed layer in the Gulf of Finland Baltic Sea. J Geophys Res 113:C05004

Publisher's note Springer Nature remains neutral with regard to jurisdictional claims in published maps and institutional affiliations. 